Pesq. Vet. Bras. 35(10):871-874, outubro 2015 DOI: 10.1590/S0100-736X2015001000009

\title{
Topografia vertebromedular de irara (Eira barbara Linnaeus, 1758) ${ }^{1}$
}

\author{
Marta Adami2*, Bruna S.S. Rekowsky², Ricardo D.G. Silva², Marcia M.M.D. Faria², \\ Maria G.F. Pinto ${ }^{2}$ e Ana E.F.S. Almeida ${ }^{2}$
}

\begin{abstract}
Adami M., Rekowsky B.S.S., Silva R.D.G., Faria M.M.M.D., Pinto M.G.F. \& Almeida A.E.F.S. 2015. [Topographic anatomy of spinal cord in tayra (Eira barbara Linnaeus, 1758).] Topografia vertebromedular de irara (Eira barbara Linnaeus, 1758). Pesquisa Veterinária Brasileira 35(10):871-874. Setor de Anatomia Veterinária, Escola de Medicina Veterinária e Zootecnia, Universidade Federal da Bahia, Av. Adhemar de Barros 500, Ondina, Salvador, BA 40170-110, Brazil. E-mail: madami@ufba.br

An adult male cadaver of a tayra (Eira barbara) was given by the Center of Triage of Wild Animals (Cetas) in Salvador, Bahia, to the Sector of Veterinary Anatomy, College of Veterinary Medicine and Animal Sciernce at the Federal University of Bahia. Eira barbara is a carnivorous mammal that belongs to the family Mustelidae, subfamily Mustelinae, and is the only species in the genus Eira. The objective of this study was to investigate the vertebro-medullary topography of the specimen and verify the relationship of the spinal chord with the spinal canal, as well as to identify and find the origin, emergence and number of spinal nerves related to the spinal chord. This study was authorized by the Biodiversity Authorization and Information System (Sisbio-ICMBio/IBAMA nr.43245-1). The specimen was fixed in a $10 \%$ solution of formaldehyde and then dissected and radiographed. Eight pairs of cervical spinal nerves and fourteen thoracic nerves were identified, as well as, in the lumbosacral portion of the spinal cord, six lumbar spinal nerves, three sacral, and more than three caudal spinal nerves. The end of the spinal chord was at the level of the fifth lumbar vertebra. The eight cervical medullary segments were found between the first and seventh cervical vertebrae. The fourteen thoracic spinal nerves originated in the cranial portion of the respective vertebrae. The medullary lumbar, sacral and caudal segments were found in the lumbar region of the backbone. The cranial displacement of the medullary segments was observed in the 8th cervical, 3rd, 4th and 5th lumbar vertebrae and all of the sacral and caudal segments. The information obtained could be used for comparative analyses with other species, to better understand the animal and for the preservation of the species.
\end{abstract}

INDEX TERMS: Anatomy, spinal cord, tayra, Eira Barbara, nervous system, wild animal.

RESUMO.- Um cadáver macho, adulto de irara (Eira barbara) foi cedido pelo Centro de Triagem de Animais Silvestres (Cetas), localizado em Salvador/Bahia, ao Setor de Anatomia Veterinária da Escola de Medicina Veterinária e Zootecnia da Universidade Federal da Bahia. Trata-se de um mamífero carnívoro que pertence à Família Mustelidae e Subfamília Mustelinae que contém o Gênero Eira, repre-

\footnotetext{
${ }^{1}$ Recebido em 5 de maio de 2015.

Aceito para publicação em 23 de setembro de 2015.

${ }^{2}$ Setor de Anatomia Veterinária, Escola de Medicina Veterinária e Zootecnia, Universidade Federal da Bahia (UFBA), Av. Adhemar de Barros 500, Ondina, Salvador, BA 40170-110, Brasil. E-mails: buh.rekowsky@ hotmail.com,drguerra@hotmail.com,mmmdf@ufba.br, pintogra@ufba. br, aelisa@ufba.br; *Autor para correspondência: madami@ufba.br
}

sentado apenas pela Espécie Eira barbara. Objetivamos a investigação da topografia vertebromedular do espécime e assim verificar a relação da medula espinal com o canal vertebral; a identificação, origem, emergência e quantificação dos nervos espinhais relacionados com a medula espinal. Pesquisa número 43245-1 autorizada pelo Sistema de Autorização e Informação em Biodiversidade (Sisbio-ICMBio/ IBAMA). 0 exemplar foi fixado em solução de formaldeído a $10 \%$ e posteriormente dissecado e radiografado. Foram identificados oito pares de nervos espinhais cervicais, quatorze torácicos e na porção lombossacral da medula espinhal seis nervos espinais lombares, três sacrais e mais de três nervos espinhais caudais. 0 término da medula espinal ocorreu no nível quinta vértebra lombar. Os oito segmentos 
medulares cervicais localizaram-se entre a primeira e sétima vértebras cervicais. Os quatorze nervos espinais torácicos originaram-se na porção cranial das vértebras respectivas. Os segmentos medulares lombares, sacrais e caudais restringiram-se à região lombar da coluna vertebral. 0 deslocamento cranial dos segmentos medulares foi observado no oitavo cervical, terceiro, quarto e quinto lombares e todos os segmentos sacrais e caudais. As informações obtidas poderão ser utilizadas para análises comparativas com as demais espécies e com a adoção de medidas que visem proporcionar o bem-estar animal e a preservação da espécie.

TERMOS DE INDEXAÇÃO: Anatomia, medula espinhal, irara, Eira barbara, sistema nervoso, animal silvestre.

\section{INTRODUÇÃO}

A irara (Eira barbara) é um mamífero pertencente à Ordem Carnívora, Família Mustelidae e Subfamília Mustelinae, que contém o Gênero Eira, representado apenas pela Espécie Eira barbara. Os mustelídeos compreendem 240 espécies e no Brasil podem ser citados a irara, ariranha, lontra e o furão. Animal onívoro conhecida como papa-mel; pode atingir um comprimento de $60 \mathrm{~cm}$ não incluindo a cauda; encontra-se desde o sul do México até a Argentina; animal escalador com hábitos diurnos, também conhecida como "cabeça de velho", pois apresenta a cabeça cinza sobre o corpo negro, com orelhas curtas e arredondadas que sugerem uma fisionomia humana (Presley 2000).

Sobre a topografia vertebromedular podem ser citados estudos realizados em veado-catingueiro, Mazama gouazoubira (Lima et al. 2010), sagui-de-tufo-branco, Callithrix jacchus (Silva et al. 2013), jabuti-de-pata-vermelha, Geochelone carbonária (Carvalho et al. 2011) e quati, Nasua nasua (Gregores 2006).

Concernente a características anatômicas do sistema nervoso em animais silvestres, podemos considerar as informações disponibilizadas escassas. A clínica e cirurgia de animais silvestres exigem o acesso a informações sobre a biologia desses animais, pois cada espécie apresenta características únicas.

Para a irara ainda não existem dados na literatura que descrevam sobre a topografia vertebromedular e assim propomo-nos investigar o assunto que poderá ser utilizado para outras pesquisas e como subsídio para procedimentos clínico e cirúrgico.

\section{MATERIAL E MÉTODOS}

Um cadáver macho, adulto de Irara (Eira barbara) foi cedido pelo Centro de Triagem de Animais Silvestres -CETAS- localizado em Salvador, Ba ao Setor de Anatomia Veterinária da Escola de Medicina Veterinária e Zootecnia da Universidade Federal da Bahia. A pesquisa foi autorizada pelo Sistema de Autorização e Informação em Biodiversidade -SISBIO- / Instituto Chico Mendes de Conservação da Biodiversidade (ICMBio) / Instituto Brasileiro de Meio Ambiente e dos Recursos Naturais Renováveis (IBAMA) no.43245-1.

Após o descongelamento, procedeu-se à fixação do material com perfusão, via artéria carótida comum, de solução de formaldeído a 10\%. O exemplar foi radiografado com aparelho de Raio-X Macrotec 500mA no Serviço Médico Veterinário (Semeve), Salvador, BA.
Para o acesso à medula espinal in situ e às radículas dos nervos espinais, procedemos à retirada da musculatura epiaxial e dos arcos vertebrais desde a transição atlanto-occipital até a base da cauda. Foi realizada a mensuração do comprimento corporal e da medula espinal com o auxílio de uma fita métrica.

A nomenclatura adotada baseou-se no International Committee on Veterinary Gross Anatomical Nomenclature (2005).

\section{RESULTADOS}

A medula espinal estendeu-se da transição atlanto-occipital até a quinta vértebra lombar e apresentou-se como um cordão cilíndrico no qual duas intumescências foram observadas: a cervical, localizada entre a quinta e sexta vértebras cervicais e a intumescência lombar com início na segunda até a terceira vértebra lombar. 0 cone medular estendeu-se da quarta à quinta vértebras lombares. 0 comprimento corporal correspondeu à $50 \mathrm{~cm}$ e o comprimento da medula foi de $41 \mathrm{~cm}$ (Fig.1).

A irara apresentou 8, 14, 6, 3 e +4 nervos espinais cervicais, torácicos, lombares, sacrais e caudais respectivamente correspondendo às $7,14,6,3$ e +4 vértebras cervicais, torácicas, lombares, sacrais e caudais. $01^{\mathrm{o}}$ par de nervo
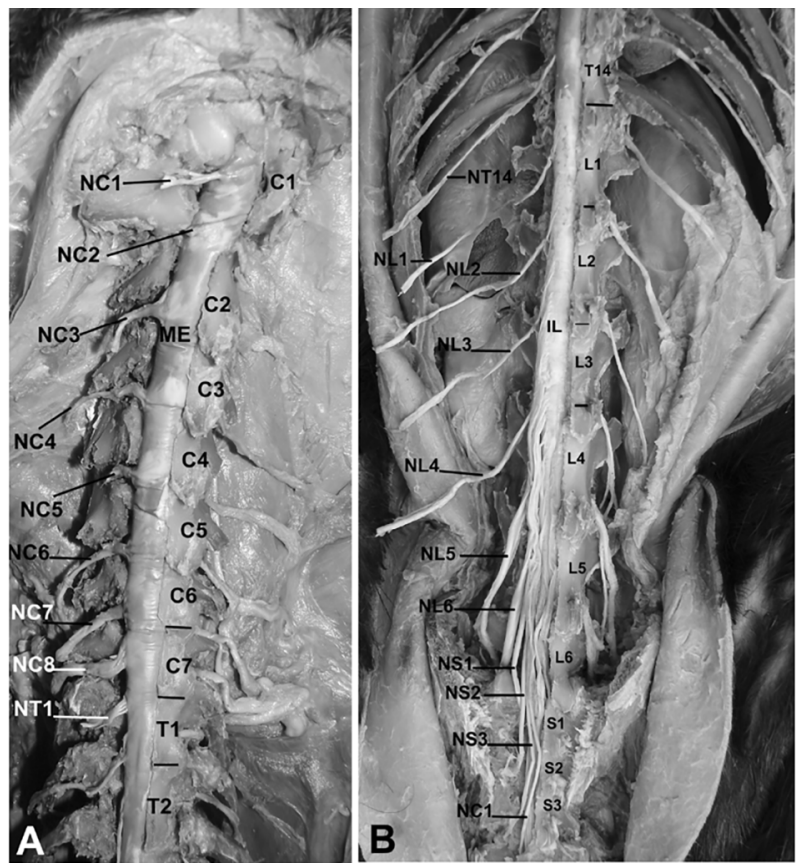

Fig.1. Vista dorsal da medula espinal e nervos espinais de irara (Eira Barbara). (A) NC1, NC2, NC3, NC4, NC5, NC6, NC7 e NC8 = primeiro, segundo, terceiro, quarto, quinto, sexto, sétimo e oitavo nervos espinais cervicais. C1, C2, C3, C4, C5, C6, C7 = primeira, segunda, terceira, quarta, quinta, sexta, sétima vértebras cervicais. $\mathrm{T} 1, \mathrm{~T} 2$ = primeira e segunda vértebras torácicas. NT1 = primeiro nervo espinhal torácico. $\mathrm{ME}=$ medula espinhal. $(-)$ = limites das vértebras. (B) T14 = décima quarta vértebra torácica. L1, L2, L3, L4, L5, L6 = primeira, segunda, terceira, quarta, quinta e sexta vértebras lombares. NL1, NL2, NL3, NL4, NL5, NL6 = primeiro, segundo, terceiro, quarto, quinto e sexto nervos espinais lombares. S1, S2, S3 = primeira, segunda e terceira vértebras sacrais. NS1, NS2, NS3 = primeiro, segundo e terceiro nervos espinhais sacrais. NC1 = primeiro nervo espinhal caudal. IL = intumescência lombar. $(-)=$ limites das vértebras. 


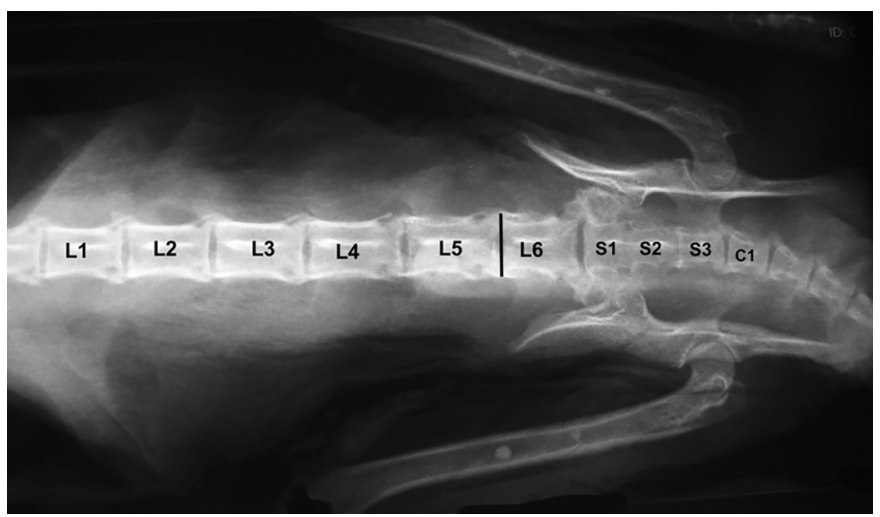

Fig.2. Radiografia ventro-dorsal de irara. L1, L2, L3, L4, L5, L6 = primeira, segunda, terceira, quarta, quinta e sexta vértebras lombares respectivamente; S1, S2, S3 = primeira, segunda e terceira vértebras sacrais respectivamente; $\mathrm{C} 1$ = primeira vértebra caudal; $(I)$ = término da medula espinal.

Quadro 1. Topografia dos segmentos medulares de irara (Eira barbara)

\begin{tabular}{lc}
\hline & Coluna vertebral \\
\hline SC & C1 a C7 \\
ST & T1 a T14 \\
SL & L1 a L3 \\
SSC & L3 a L5 \\
CM & L4 a L5
\end{tabular}

SC = segmento cervical, $\mathrm{ST}=$ segmento torácico, $\mathrm{SL}=$ segmento lombar, SSC = segment sacrocaudal, $\mathrm{CM}=$ cone medular, $\mathrm{C} 1$ a $\mathrm{C7}$ = primeira a sétima vértebras cervicais, $\mathrm{T} 1$ a T14 = primeira a décima quarta vértebras torácicas, L1 a L3 = primeira a terceira vértebras lombares, L3 a L5 = terceira a quinta vértebras lombares, L4 a L5 = quarta a quinta vértebras lombares.

espinal cervical emergiu através do forame do processo transverso do atlas. Do segundo ao sétimo pares de nervos espinais a origem e emergência ocorreram ao nível do forame intervertebral cranial à vértebra correspondente. Em relação ao oitavo par de nervo espinal cervical, foi possível identificar a origem no nível do terço médio da sétima vértebra cervical e emergência no forame intervertebral entre a sétima vértebra cervical e a primeira vértebra torácica (Fig.1 e 2).

No segmento torácico todos os pares de nervos espinais apresentaram origem na porção cranial da vértebra correspondente.

Na porção lombar da medula espinal o primeiro e segundo pares de nervos espinais lombares originaram-se na porção cranial das vértebras respectivas. 0 terceiro par de nervo espinal lombar originou-se no terço médio da segunda vértebra lombar e o quarto, quinto e sexto nervos espinais lombares originaram-se no nível da terceira vértebra lombar. A partir do terço caudal da terceira até a quinta vértebras lombares ocorreu a origem dos nervos espinais sacrais e caudais (Quadro 1).

\section{DISCUSSÃO}

Na irara a porção cervical da medula espinal terminou no nível da sétima vértebra cervical, apesar da presença de um segmento medular adicional. Considera-se segmen- to medular de um determinado nervo a parte da medula espinal onde fazem conexão os filamentos radiculares mais a região cranial e caudal às radículas que entram na composição deste nervo (Maierl \& Liebich 1998, Machado 2000).

Em búfalos (Sharma \& Rao 1971) a mesma configuração foi observada, porém na impala (Rao et al. 1993) foi descrito deslocamento cranial do segundo ao oitavo segmentos medulares em relação às respectivas vértebras, embora 0 primeiro segmento medular torácico localizou-se no limite da vértebra correspondente.

Na região medular torácica de irara os quatorze segmentos medulares torácicos localizaram-se no nível das respectivas vértebras, configuração também descrita nos treze segmentos medulares torácicos presentes em veadocatingueiro (Lima et al. 2010). Em impala (Rao et al. 1993) e em búfalo (Sharma \& Rao 1971) foi registrado deslocamento cranial e caudal dos segmentos medulares torácicos em relação às vértebras de mesma numeração. Em irara não observamos em nenhuma região da medula espinal descenso medular, no entanto, em gatos, Lima et al (2010) observaram descenso medular na região toracolombar, com o décimo terceiro segmento torácico relacionando-se com a primeira vértebra lombar.

Em irara todos os segmentos medulares lombares, sacrais e caudais ficaram restritos à região lombar da coluna vertebral, o que não ocorreu em búfalo, cuja porção sacral da medula espinal estendeu-se até a segunda vértebra sacral e os segmentos coccígeos localizaram-se na terceira vértebra sacral (Sharma \& Rao 1971). Em sagui-de-tufo-branco, com o término da medula espinal no nível da quinta vértebra lombar (Silva et al. 2013), indica-se que os segmentos medulares lombar, sacral e caudal também estejam localizados na região lombar da coluna vertebral. Na impala, com a presença de seis vértebras lombares, todos os segmentos medulares caudais a quarta vértebra deslocaram-se cranialmente às respectivas vértebras, porém a medula espinal terminou no nível da segunda vértebra sacral (Rao et al. 1993).

Branco et al. (2013) ao descreverem sobre a topografia do cone medular de irara, relataram o término da medula espinal no nível da quinta ou sexta vértebra lombar. Em ariranha o término da medula espinal ocorreu no nível da quarta vértebra lombar, com a presença de sete vértebras lombares (Machado et al. 2009). Portanto, podemos deduzir que os segmentos medulares lombares, sacrais e caudais, à semelhança de nossos resultados, estejam também restritos à região lombar nesses exemplares da Família Mustelidae.

Em coelhos foi registrado a presença de seis a sete nervos espinais lombares e quatro nervos espinais sacrais com localização restrita a região lombar da coluna vertebral, apesar de a medula espinal terminar na região sacral da coluna vertebral (Greenaway et al. 2001).

Concernente ao cone medular de irara, estendeu-se mais cranialmente, entre a quarta e quinta vértebras lombares, ao contrário das observações de Branco et al. (2013) que descreveram a posição do cone medular entre a terceira ou quarta à sexta vértebras lombares. Ainda na Família 
Mustelidae, Machado et al. (2009) descreveram em ariranha sua situação entre a segunda à quarta vértebras lombares e com a presença de sete vértebras lombares.

A intumescência cervical de irara apresentou-se no mesmo nível quando comparada com a do jabuti de patas-vermelhas (Geochelone carbonária) constituída pelo quinto, sexto, sétimo e oitavo segmentos medulares cervicais e primeiro segmento torácico (Carvalho et al. 2011). Em veado-catingueiro (Mazama gouazoubira) (Lima et al. 2010) e em quati (Nasua nasua) (Gregores 2006) a intumescência cervical estendeu-se da quarta vértebra cervical à primeira vértebra torácica e em sagui-de-tufo-branco (Callithrix jacchus) (Silva et al. 2013) localizou-se entre a quarta ou quinta vértebras cervicais a quarta ou quinta vértebras torácicas, o que revelou um maior comprimento dessa estrutura em outras espécies silvestres.

Branco et al (2013) registraram em irara localização semelhante da intumescência lombar, porém ao compará-la com a do veado-catingueiro, Mazama gouazoubira (Lima et al. 2010) e cachorro-do-mato-de-orelhas-pequenas, Atelocynus microtis) (Saldanha et al. 2011), a intumescência lombar de irara apresentou menor comprimento, pois naquelas duas espécies estendeu-se da terceira à sexta vértebras lombares. Concernente à ariranha (Pteronura brasiliensis), espécie também pertencente à Família Mustelidae, a intumescência lombar apresentou deslocamento cranial, encontrando-se entre a décima segunda vértebra torácica e à segunda vértebra lombar (Machado et al. 2009).

As regiões medulares cervical e torácica de irara apresentaram equivalência com as vértebras respectivas. A presença de deslocamento cranial foi a partir da região lombar da medula espinal, que determinou o seu término na região lombar da coluna vertebral, característica anatômica que favorece o sítio lombossacral da coluna vertebral para a utilização de anestesias meníngeas.

Os resultados obtidos foram comparados com animais de variadas taxonomias devido à restrição de estudos relacionados com a topografia vertebromedular em animais silvestres.

\section{REFERÊNCIAS}

Branco E., Lins e Lins F.L.M., Pereira L.C. \& Lima A.R. 2013. Topografia do cone medular da irara (Eira barbara) e sua relevância em anestesias epidurais. Pesq. Vet. 33:813-816.

Carvalho R.C., Sousa A.L., Oliveira S.C.R., Pinto A.C.B.C.F., Fontenelle J.H. \& Cortopassi S.R.G. 2011. Morphology and topographic anatomy of the spinal cord of the red-footed tortoise (Geochelone carbonaria Spix, 1824). Pesq. Vet. Bras. 31:47-52.

Greenaway J.B., Partlow G.D., Gonsholt N.L. \& Fisher K.R.S. 2001. Anatomy of the lumbosacral spinal cord in rabbits. J. Am. Anim. Hospital Assoc. 37:27-34.

Gregores G.B. 2006. Topografia vértebro-medular e anesthesia espinhal em quati (Nasua nasua). Dissertação de Mestrado em Ciências, Faculdade de Medicina Veterinária e Zootecnia, Universidade de São Paulo, São Paulo, SP. 70p.

International Committee on Veterinary Gross Anatomical Nomenclature 2005. Nomina Anatomica Veterinaria. 5th ed. World Association on Veterinary Anatomist, Knonxville. 190p.

Lima F.C., Santos A.L.Q., Lima B.C., Vieira L.G. \& Hirano L.Q.L. 2010. Topography anatomy of the spinal corde and vertebromedullary relationships in Mazama gouazoubira Fisher, 1814 (Artiodactyla: Cervidae). Acta Scientiarum, Biological Sciences 32:189-194.

Machado A. 2000. Neuroanatomia Funcional. 2nd ed. Atheneu, São Paulo. 363p.

Machado G.V., Rosas F.C.W. \& Lazzarini S.M. 2009. Topografia do cone medular na ariranha (Pteronura brasiliensis Zimmermann, 1870). Ciênc. Anim. Bras. 10:301-305.

Maierl J. \& Liebich H.G. 1998. Investigations on the postnatal development of the macroscopic proportions and the topographic anatomy of the feline spinal cord. Anat. Histol. Embryol. 27:375-379.

Presley S.J. 2000. Mammalian Species: Eira barbara. Am. Soc. Mammalogists, Lawrence. 636p.

Rao G.S., Kalt D.J., Koch M. \& Majok A.A. 1993. Anatomical studies on the spinal cord segments of the Impala (Aepyceros malampus). Anat. Histol. Embryol. 22:273-278.

Saldanha K.L., Branco E. \& Lima A.R. 2011. Topografia do cone medular do cachorro-do-mato-de-orelhas-pequenas (Atelocynus microtis Sclater, 1822): relato de caso. Biotemas 24:135-139.

Sharma D.N. \& Rao G.S. 1971. Topography of spinal cord segments in buffalo (Bubalus bubalis). Indian J. Anim. Sci. 41:161-165.

Silva L.L.S., Barroso C.E., Junior V.P. \& Bombonato P.P. 2013. Topografia vértebro-medular em sagui-de-tufo-branco (Callithrix jacchus Linnaeus, 1758). Ciênc. Anim. Bras. 14:462-467. 